\title{
Is uveitis associated with topiramate use? A cumulative review
}

This article was published in the following Dove Press journal:

Clinical Ophthalmology

2 August 2016

Number of times this article has been viewed

Jeffrey L Goldberg'

Amy G Lau ${ }^{2}$

Bo $\mathrm{Fan}^{2}$

Lisa Ford ${ }^{3}$

Howard E Greenberg ${ }^{3}$

'Byers Eye Institute, Stanford University, Palo Alto, CA, ${ }^{2}$ Janssen

Research \& Development, LLC, Horsham, PA, J3anssen Research \&

Development, LLC, Titusville, NJ, USA
Correspondence: Jeffrey L Goldberg Byers Eye Institute, Stanford University, 2452 Watson Ct, Palo Alto, CA 94304, USA

$\mathrm{Tel}+\mathrm{I} 9166507236137$

Email jeffrey.goldberg@stanford.edu
Abstract: Occasional reports of uveitis following topiramate use necessitated an investigation of relevant cases from safety databases and published biomedical literature. Data mining of the Food and Drug Administration Adverse Event Reporting System and cumulative review of cases from the global safety database (sponsor database) and published literature were conducted to assess association between topiramate use and uveitis. The Food and Drug Administration Adverse Event Reporting System search identified disproportional reporting of uveitis $(n=23)$ and related terms (choroidal detachment, $n=25$; iridocyclitis, $n=17$ ). The postmarketing reporting frequency of uveitis and related events from the global safety database and based on an estimated topiramate exposure of 11,185,740 person-years from launch to April 2015 was 0.38 per 100,000 person-years and assigned as very rare. A total of 14 potential uveitis cases were identified from the cumulative review. Seven of these 14 cases were complicated by inadequate documentation, appearance of uveitic signs following drug withdrawal, or concurrent use of other sulfonamides. In acute angle-closure glaucoma and uveal effusions cases, insufficient evidence for underlying inflammation suggested that uveitis was not a component. Only seven of 14 cases were well documented, potentially topiramate-associated uveitis cases. Uveitis may occur in the setting of topiramate use only in very rare instances. Current evidence did not reveal a dose- or duration-dependent relationship between uveitis and topiramate use.

Keywords: topiramate, uveitis, acute angle-closure glaucoma, drug safety, Food and Drug Administration Adverse Event Reporting System, postmarketing

\section{Introduction}

Uveitis generally arises as a local inflammatory response or as a part of a systemic inflammatory or autoimmune process and is seldom associated with acute angle-closure glaucoma (AACG). ${ }^{1}$ Topiramate, a sulfamate-substituted monosaccharide, was first approved by the US Food and Drug Administration (FDA) in 1996 to prevent seizures and for migraine prevention in adults and adolescents in 2004 and 2014, respectively. Topiramate acts by blocking of sodium channels, potentiation of inhibitory gammaaminobutyrate, and antagonism of kainate/alpha-amino-3-hydroxy-5-methylisoxazole4-propionic acid subtype of excitatory glutamate receptor. ${ }^{2}$

To date, exposure to topiramate is estimated to be 11,185,740 person-years from launch to April 30, 2015. Data mining from the FDA Adverse Event Reporting System (FAERS) provided initial signals of elevated empirical Bayes geometric mean (EBGM) scores for topiramate-associated uveitis and related terms. Association between topiramate and uveitis has also been postulated from a published case report. ${ }^{3}$ Data mining of the FAERS and a comprehensive review of cases from the global safety database (global SD; a sponsor database which allows collection, analysis, and reporting of individual case safety reports) and published biomedical literature were, therefore, 
undertaken to examine whether a reliable link and a safety issue exists for topiramate use and uveitis.

\section{Methods}

The publicly accessible FAERS was searched through the second quarter of 2014 for spontaneous cases of topiramateassociated uveitis and related terms (choroidal detachment and iridocyclitis). All spontaneous and clinical study cases of uveitis that included topiramate as either a suspect, suspect-interacting, or concomitant medication were retrieved from the global SD cumulatively through April 30, 2015. Specific Medical Dictionary for Regulatory Activities (MedDRA, version 18.0) preferred terms used in this analysis were uveitis, chorioretinitis, choroidal detachment, choroiditis, cyclitis, iridocyclitis, iritis, noninfective chorioretinitis, and retinitis. Biomedical databases (MEDLINE, Derwent Drug File, Embase, and BIOSIS) were also searched for all case reports or articles using keywords related to topiramate and events suggestive of uveitis on June 10, 2015. All identified cases were evaluated for clinical history assessing potential relationship between topiramate and uveitis.

\section{Results}

\section{Data mining results from the FAERS}

The FAERS search identified disproportional reporting for uveitis ( $\mathrm{n}=23$; EBGM =3.466) and related terms (choroidal detachment, $\mathrm{n}=25, \mathrm{EBGM}=71.888$; iridocyclitis, $\mathrm{n}=17$, $\mathrm{EBGM}=8.768$ ) with topiramate use.

\section{Cases reported in the global SD}

There were 43 spontaneous cases reporting uveitis in patients who received topiramate, of which 29 were eliminated as not meeting the criteria, and thus 14 cases were selected and further reviewed (Table 1). Four of these 14 cases retrieved from the global SD were also reported in the published literature discussed in the following section. ${ }^{3-6}$ Seven cases

Table I Disposition of cases from the global safety database suggestive of uveitis with topiramate

\begin{tabular}{ll}
\hline Case subset & $\begin{array}{l}\text { Number } \\
\text { of cases }\end{array}$ \\
\hline All cases & 43 \\
Insufficient information & 9 \\
Not considered uveitis & 9 \\
Implausible latency & 7 \\
Confounding medical history/comorbid condition & 2 \\
Negative dechallenge & $\mathrm{I}$ \\
Multiple unidentified patients & $\mathrm{I}$ \\
Selected cases for detailed review & $\mathrm{I} 4$ \\
\hline
\end{tabular}

presented specific uveitic features, and four cases reported uveitis without documentation of uveitic signs and appeared to be unlikely to have used the diagnostic terms appropriately. The remaining three cases received treatment with steroids or prednisolone, but without documentation of ocular symptoms or signs of uveitis. Two of these cases reported delayed symptoms emerging upon initiating other oral and topical sulfa drugs, one of which was also described in the published literature ${ }^{6}$ (Table 2).

Overall, based on the 43 spontaneous cases reported and an estimated total exposure of $11,185,740$ person-years, the postmarketing reporting frequency for the preferred terms was calculated as 0.38 cases per 100,000 person-years and, hence, attributed as very rare.

\section{Cases reported in the published literature}

A search of biomedical literature databases retrieved 279 citations, of which only eight cases $^{3-9}$ reported potential relationship of uveitis with topiramate use (Table 3). Three of the eight cases reported intraocular inflammation and were sufficiently documented to assess an association of uveitis with topiramate therapy. ${ }^{3-5}$ Of the three cases, only one documented a systemic uveitic workup that was negative for inflammatory or autoimmune diseases, and the patient responded to steroid therapy. ${ }^{5}$ Two other cases ${ }^{6,7}$ documented uveitis that was suggestive of cross-reactivity to sulfa-analog drugs as a proximate cause.

Table 2 Summary of reviewed cases from the global safety database

\begin{tabular}{|c|c|}
\hline Cases identified from the global safety database & $N=14$ \\
\hline Cases identifying specified uveitic features & 7 \\
\hline Iridocyclitis, treated with prednisolone & 1 \\
\hline $\begin{array}{l}\text { Iritis (treatment not specified or not reporting specific } \\
\text { treatment other than topiramate withdrawal) }\end{array}$ & 3 \\
\hline Severe anterior uveitis $^{\mathrm{a}}$ & 3 \\
\hline $\begin{array}{l}\text { Cases reporting uveitis without documenting } \\
\text { signs or unlikely to have used the diagnostic } \\
\text { terms appropriately }\end{array}$ & 4 \\
\hline Choroidal effusion and choroiditis & 1 \\
\hline $\begin{array}{l}\text { Uveitis not further characterized and not reported as } \\
\text { treated, other than withdrawing topiramate }\end{array}$ & 1 \\
\hline Periorbital swelling and distension and uveitis & 1 \\
\hline AACG with effusion, but no uveitic signs reported ${ }^{b}$ & 1 \\
\hline $\begin{array}{l}\text { Cases reporting treatment with steroids or } \\
\text { prednisolone, but without documenting ocular } \\
\text { symptoms of uveitisc }\end{array}$ & 3 \\
\hline
\end{tabular}

Notes: ${ }^{a} \mathrm{All}$ three cases also identified in published literature search. ${ }^{3-5}{ }^{\mathrm{b}} \mathrm{Case}$ also reported in Chen et al. ${ }^{20}$ Cne of three cases also identified in published literature search. ${ }^{6}$

Abbreviation: AACG, acute angle-closure glaucoma. 
Table 3 Summary of reviewed cases from published literature

\begin{tabular}{ll}
\hline Cases identified from published literature & $\mathbf{N}=\mathbf{8}$ \\
\hline Cases of intraocular inflammation $^{\mathrm{a}}$ & 3 \\
Strong AC reaction with 4+ cells from day I of & $\mathrm{I}$ \\
presentation & \\
Idiosyncratic AC reaction with 4+ cells & \\
Initial I+ AC cell reaction and vitritis, followed by a & $\mathrm{I}$ \\
$\begin{array}{l}\text { stronger reaction with hypopyon } \\
\text { 5,b }\end{array}$ & $\mathrm{I}$ \\
$\begin{array}{l}\text { Cases of uveitis after stopping topiramate and initiating } \\
\text { other sulfa derivatives (dorzolamide or acetazolamide) }\end{array}$ & 2 \\
$\begin{array}{l}\text { Cases of no inflammation, but resolution of AACG after } \\
\text { methylprednisolone therapy }\end{array}$ & 3 \\
\hline
\end{tabular}

Notes: a Cases also retrieved from the global safety database. ${ }^{b}$ Systemic workup undertaken.

Abbreviations: AACG, acute angle-closure glaucoma; AC, anterior chamber.

\section{Cases without documented uveitis, but with sequelae of AACG}

The remaining three of eight cases in two published reports ${ }^{8,9}$ documented uveitic clinical findings that are also associated with the iris ischemia found in AACG, including cells in the anterior chamber (AC) and fibrosis or synechiae that occurred after presentation. Such events could potentially indicate uveitic reactions or could be the normal sequelae of an ischemic insult associated with AACG, which can release cells from the ischemic iris into the $\mathrm{AC}$ and/or lead to chronic fibrotic reactions.

An example that illustrates both putative explanations was found in a case report that noted flare, that is, protein release from ischemic iris vessels that can be attributable to ischemia of AACG, but no cells in the AC. ${ }^{9}$ This patient was treated with acetazolamide, which, as a second sulfaderivative drug, could have elicited an inflammatory crossreactivity, and then methylprednisolone. Later, a 1-month follow-up showed posterior synechiae, not commented on previously. A similar pair of AACG cases did not document any clinical signs of uveitis, but one case was treated with topical steroids and ended with peripheral anterior synechiae ${ }^{8}$ (Table 3).

\section{Cases documenting uveal or choroidal effusions as the cause of topiramate-induced AACG}

Serous effusions including those associated with topiramate therapy ${ }^{10}$ are generally not thought to be inflammatory when there is no other sign of uveitis, although inflammation can also cause effusions. ${ }^{11}$ One report associated topiramate therapy with choroidal effusions or detachments without any inflammation or even angle closure; the shared sulfa reactivity to dorzolamide was again noted in this case. ${ }^{12}$

\section{Discussion}

Sporadic reports of uveitis related to topiramate use from the published biomedical literature and disproportionate reporting in the FAERS prompted this cumulative review. Inconsistencies in reporting have also been observed in several reviews that discuss topiramate-induced AACG without any mention of uveitis, ${ }^{13,14}$ or uveitis and glaucoma without any link to topiramate,${ }^{15}$ or topiramate and uveal effusions as an idiosyncratic response leading to AACG, but not identifying uveitis as a cause of effusion or sequela of topiramate. ${ }^{16,17}$ Based on the postmarketing reporting frequency from the global SD analysis ( 0.38 cases per 100,000 person-years), uveitis occurs in very rare instances in topiramate-treated patients. Now, with a broader analysis of cases from the global SD and published literature, 14 potential cases have been identified, of which only seven demonstrated welldocumented uveitic presentations. In contrast, seven cases were confounded by inadequate documentation of uveitic signs or topiramate therapy or by documentation of uveitic signs only upon withdrawal of topiramate or initiation of other sulfonamide therapeutics and, therefore, excluded for not meeting the criteria for topiramate-related uveitis. Since both AACG and uveitis are not subtle presentations, it is unlikely that significant uveitis is underdiagnosed. Thus, only seven well-documented cases adequately relate uveitis with topiramate therapy among all identified cases representing approximately $11,185,740$ person-years of topiramate exposure in the approximate 20 -year period from launch of the drug to April 30, 2015.

Furthermore, there is little evidence to attribute uveitis as a proximate cause of cases of AACG, or of uveal effusions in topiramate-associated AACG. Generally, AACG does not lead to uveitis, although it can elicit similar, albeit misleading signs, such as cells in the AC.

Our analysis extends and is consistent with general reviews discussing the visual effects of topiramate therapy. ${ }^{18,19}$ A comprehensive review cited a subset of uveitis cases described in this analysis, noting the rare and idiosyncratic, nondose-dependent nature of these reported cases $;{ }^{18}$ a second review on ocular toxicities of systemic drugs including topiramate ${ }^{19}$ mentioned one of the cases presented herein. ${ }^{5}$

\section{Conclusion}

The analysis of available reports leads to a conclusion that uveitis is not associated with topiramate use, and may occur only in very rare instances without clear evidence for dose- or duration-dependence. 


\section{Acknowledgments}

The authors thank Dr Phillip F Pierce (Janssen Research \& Development, LLC, NJ, USA) for useful discussions. Priya Ganpathy (SIRO Clinpharm Pvt Ltd) provided writing assistance and Dr Ellen Baum (Janssen Research \& Development, LLC) provided additional editorial support for development of the manuscript.

\section{Author contributions}

Dr Goldberg was involved in data evaluation, interpretation, and drafting of the manuscript. Drs Ford, Greenberg, and Lau were also involved in data evaluation and interpretation. Drs Lau and Fan contributed to background investigations, and Drs Ford and Greenberg were involved in critical revision of the manuscript for intellectual content. All authors critically reviewed and approved the final manuscript. All authors met the ICMJE criteria, and all those who fulfilled those criteria are listed as authors. All authors had access to the study data and made the final decision about where to publish these data and approved submission to this journal.

\section{Disclosure}

Drs Ford, Lau, Fan, and Greenberg are employees of Janssen and hold company stocks. Dr Goldberg has received honoraria as a consultant from Janssen, Allergan (Parsippany, NJ, USA), and Theravance (South San Francisco, CA, USA). This study was funded by Janssen Research \& Development, LLC. The sponsor also provided a formal review of the manuscript. The authors report no other conflicts of interest in this work.

\section{References}

1. Dunn JP. Uveitis. Prim Care. 2015;42(3):305-323.

2. Shank RP, Gardocki JF, Streeter AJ, Maryanoff BE. An overview of the preclinical aspects of topiramate: pharmacology, pharmacokinetics, and mechanism of action. Epilepsia. 2000;41 Suppl 1:S3-S9.
3. Dhar SK, Sharma V, Kapoor G, Seshadri KP, Chauhan VS. Topiramate induced bilateral anterior uveitis with choroidal detachment and angle closure glaucoma. Med J Armed Forces India. 2015;71(1):88-91.

4. Acharya N, Nithyanandam S, Kamat S. Topiramate-associated bilateral anterior uveitis and angle closure glaucoma. Indian J Ophthalmol. 2010; 58(6):557-559

5. Jabbarpoor Bonyadi MH, Soheilian R, Soheilian M. Topiramate-induced bilateral anterior uveitis associated with hypopyon formation. Ocul Immunol Inflamm. 2011;19(1):86-88.

6. Katsimpris JM, Katsimpris A, Theoulakis PE, Lepidas J, Petropoulos IK. Bilateral severe anterior uveitis and acute angle-closure glaucoma following topiramate use for migraine crisis. Klin Monbl Augenheilkd. 2014:231(4):439-441.

7. Kamal S, Yadava U, Kumar S, Goel R. Topiramate-induced angleclosure glaucoma: cross-sensitivity with other sulphonamide derivatives causing anterior uveitis. Int Ophthalmol. 2014;34(2):345-349.

8. Aminlari A, East M, Wei W, Quillen D. Topiramate induced acute angle closure glaucoma. Open Ophthalmol J. 2008;2:46-47.

9. Pikkel YY. Acute bilateral glaucoma and panuveitis as a side effect of topiramate for weight loss treatment. BMJ Case Rep. 2014;2014.

10. Chen TC, Chao CW, Sorkin JA. Topiramate induced myopic shift and angle closure glaucoma. Br J Ophthalmol. 2003;87(5):648-649.

11. Bakir B, Pasquale LR. Causes and treatment of choroidal effusion after glaucoma surgery. Semin Ophthalmol. 2014;29(5-6):409-413.

12. Dehghani A, Abtahi MA, Abtahi SH, et al. Massive bilateral choroidal detachment induced by administration of topiramate. Case Rep Ophthalmol. 2011;2(2):251-255.

13. Fraunfelder FW. Ocular adverse drug reactions and the National Registry of Drug-Induced Ocular Side Effects. Insight. 2004;29(2):7-11.

14. Reeks GA, Ang GS. Follow-up of suspected ocular adverse drug reactions. Acta Ophthalmol. 2010;88(7):e279-e280.

15. Panek WC, Holland GN, Lee DA, Christensen RE. Glaucoma in patients with uveitis. Br J Ophthalmol. 1990;74(4):223-227.

16. Lachkar Y, Bouassida W. Drug-induced acute angle closure glaucoma. Curr Opin Ophthalmol. 2007;18(2):129-133.

17. Rapoport Y, Benegas N, Kuchtey RW, Joos KM. Acute myopia and angle closure glaucoma from topiramate in a seven-year-old: a case report and review of the literature. BMC Pediatr. 2014;14:96.

18. Abtahi MA, Abtahi SH, Fazel F, et al. Topiramate and the vision: a systematic review. Clin Ophthalmol. 2012;6:117-131.

19. Gokulgandhi MR, Vadlapudi AD, Mitra AK. Ocular toxicity from systemically administered xenobiotics. Expert Opin Drug Metab Toxicol. 2012;8(10):1277-1291.

20. Chen S-L, Sheu S-J, Chang S-E. [Acute visual impairment induced by diet pill: A case report]. Acta Soc Ophthalmol Sinicae. 2013;52(2): 122-127. Chinese.
Clinical Ophthalmology

\section{Publish your work in this journal}

Clinical Ophthalmology is an international, peer-reviewed journal covering all subspecialties within ophthalmology. Key topics include: Optometry; Visual science; Pharmacology and drug therapy in eye diseases; Basic Sciences; Primary and Secondary eye care; Patient Safety and Quality of Care Improvements. This journal is indexed on

\section{Dovepress}

PubMed Central and CAS, and is the official journal of The Society of Clinical Ophthalmology (SCO). The manuscript management system is completely online and includes a very quick and fair peer-review system, which is all easy to use. Visit http://www.dovepress.com/ testimonials.php to read real quotes from published authors. 